\title{
Quantitative Analysis of Peroxisomal Protein Import in Vitro
}

\author{
Stanley R. Terlecky,*,1 J ulie E. Legakis,* Sarah E. Hueni,* and Suresh Subramani† \\ *Department of Pharmacology, Wayne State University School of Medicine, 540 East Canfield Avenue, Detroit, Michigan 48201 ; and \\ †Department of Biology, University of California at San Diego, Bonner Hall, 9500 Gilman Drive, La J olla, California 92093-0322
}

Protein import into the peroxisome matrix is mediated by peroxisome-targeting signals (PTSs). We have developed a novel, quantitative, in vitro assay for measuring peroxisomal import of PTS1-containing proteins. This enzyme-linked immunosorbent assay-based system utilizes semi-intact human A431 cells or fibroblasts and a biotinylated version of the PTS1-containing import substrate, luciferase. We show that biotinylated luciferase accumulated in peroxisomes in a time- and temperature-dependent fashion, in a reaction stimulated by exogenously added ATP, cytosol, and zinc. No import was detected in fibroblasts from a human patient belonging to complementation group 2 , who suffered from the fatal peroxisomal disorder Zellweger syndrome and lacked a functional PTS1 receptor, Pex5p. Also, the reaction was significantly inhibited by antibodies to the zinc-finger protein, Pex2p. Several lines of evidence demonstrate that biotinylated luciferase was imported into the lumen of bona fide peroxisomes. (a) Biochemical fractionation of cells after the import reaction showed a time-dependent accumulation of the import substrate within intracelIular organelles. (b) Confocal fluorescence microscopy indicated that imported biotinylated luciferase colocalized with the peroxisomal protein PMP70. (c) Visualization of the imported biotinylated luciferase by indirect fluorescence or indirect immunofluorescence required disruption of the peroxisomal membrane, indicating true import rather than binding to the outside of the organelle. $\odot 2001$ Academic Press

Key Words: membrane; organelle; peroxisome matrix; protein targeting; zinc.

\section{INTRODUCTION}

Peroxisomes amass their constituent enzymes via mechanisms that resemble, in many ways, protein import systems found in other organelles. Peroxisomes, like chloroplasts, endoplasmic reticulum, and mitochondria, require the presence of targeting signals on import substrates, a receptor system for their recogni-

\footnotetext{
${ }^{1}$ To whom correspondence and reprint requests should be addressed. Fax: (313) 577-6739. E-mail: s.r.terlecky@wayne.edu.
}

tion, and a membrane-associated translocation apparatus. Despite these apparent similarities, in recent years it has become increasingly clear that peroxisomal enzymes are directed to, and imported into, the organelle by a molecular machinery whose components, mechanisms, and regulation are unmistakably unique.

For example, peroxisomal enzymes are imported without a requirement that they be unfolded. Indeed, fully folded, chemically stabilized proteins with a $\mathrm{PTS}^{2}$ sequence are imported-as are gold particles coupled to a PTS1 sequence [1]. In some cases, oligomeric proteins enter peroxisomes as assembled complexes [2, 3]. Despite the apparent absence of global unfolding of import substrates, peroxisomal protein import does require action of the chaperone, Hsc70 [4]. Hsc70 accumulates on the peroxisome membrane under conditions of stimulated import, but its functional role remains unclear. Other chaperones, Hsp90, and Djplp have also been implicated in facilitating peroxisomal protein import $[5,6]$, but their mechanism of action is not well understood.

Nearly all peroxisomal enzymes are directed to the organelle by virtue of the tripeptide serine-lysineleucine, or a biochemical variant, at their carboxy termini [7]. This topogenic determinant, called PTS1, is recognized in a high-affinity interaction by the receptor molecule Pex5p [8]. This receptor protein appears to shuttle between the cytosol and the peroxisome [9]. Although an understanding of how Pex $5 p$ functions mechanistically to facilitate import is not yet worked out, the basis of its association with the peroxisome is. Mammalian Pex5p interacts with the peroxisome via at least two membrane docking proteins, Pex13p [10] and Pex14p [11]. Therefore, import complexes presumably exist as some combination of Pex $5 p$, Pex $13 p$, Pex14p, the PTS1 substrate, and other unidentified components. A major goal of current efforts in the field of peroxisome biology is to identify these unknown

\footnotetext{
${ }^{2}$ Abbreviations used: BSA, bovine serum albumin; $\mathrm{CHO}$, Chinese hamster ovary; DMSO, dimethyl sulfoxide; ELISA, enzyme-linked immunosorbent assay; FITC, fluorescein isothiocyanate; Hsc70, heat shock cognate protein; IRB, import reaction buffer; $L D H$, lactate dehydrogenase; PBS, phosphate-buffered saline; PMP70, peroxisomal membrane protein of $70 \mathrm{kDa}$; PTS1, peroxisomal targeting signal 1.
} 
factors and to decipher the underlying molecular mechanisms of import.

There is added urgency in advancing these studies as, in humans, there exist a number of fatal disorders in which peroxisomes fail to import PTS1-containing enzymes [12, 13]. Peroxisome biogenesis disorders are manifest at birth and affected children most often die within the first decade of life.

Genetic and biochemical approaches have been applied to the study of peroxisomal protein import and biogenesis, with each contributing new and important insights. Genetic screens for peroxisomal import mutants in a number of organisms have led to the description of some 23 genes which encode proteins, called peroxins, involved in various aspects of peroxisome assembly [14, 15]. Biochemical approaches have complemented and extended these studies. Indeed, several important observations regarding the properties of import have been delineated through the use of in vitro systems, in which the process of peroxisomal protein import has been reconstituted.

In vitro peroxisomal import assays fall into three broad categories: (1) those which utilize purified peroxisomes, (2) those based on microinjection of substrates into intact cells, and (3) those employing semipermeabilized cells.

Using protease protection as the hallmark of import, radiolabeled substrates have been incubated in in vitro import reactions with purified rat liver [16] or yeast peroxisomes [17]. In rat liver, these experiments showed that import of the PTS1-containing substrate acyl-CoA oxidase was ATP-, time-, temperature-, and signal-dependent [16]. Unfortunately, organelle instability and questions regarding the import proficiencies of peroxisome subpopulations have prevented the assay from becoming more universally utilized. A second approach was developed in which peroxisomal substrates were microinjected into cells and import was detected over time by immunofluorescence. These studies revealed a requirement for the molecular chaperone Hsc70 [4], as well as the inability of cells of patients from specific complementation groups of the fatal disorder, Zellweger syndrome, to import peroxisomal substrates [18]. Also, this experimental paradigm led to the conclusions that there existed no discernible differences in the import competencies among peroxisomes in a given mammalian cell [19] and that, as described above, obligate unfolding of import substrates was not required [1].

An immunofluorescence-based import assay using permeabilized cells has proved to be an extremely effective alternative to its predecessors. The assay, developed by Wendland and Subramani [20], relies on the properties of the bacterial toxin streptolysin-O, which permeabilizes plasma, but not peroxisomal, membranes. After this selective fenestration of the cell's outer membranes, import substrates (e.g., human serum albumin enzymatically coupled to a PTS1 peptide) and various biochemical factors are allowed to diffuse into the cell. Import is assessed by indirect immunofluorescence-specifically looking for the import substrate to appear in punctate structures. That these structures are actually peroxisomes is then confirmed by their colocalization with bona fide peroxisomal marker proteins. In addition to the properties revealed by the other approaches, this assay has been used to demonstrate a direct requirement for cytosolic factors, in general [20], and for Pex5p [21] and Pex14p [11] in particular.

The assay described in this report also faithfully recapitulates import into peroxisomes-but does so in a manner that is, for the first time, truly quantitative. The assay also utilizes semipermeabilized cells and includes a biotinylated import substrate, specifically, the PTS1-containing enzyme luciferase. To ensure that no unimported biotinylated luciferase is included in the measurement, the bi otin groups on these molecules are masked with avidin and the excess avidin is quenched with biocytin. The basis of the assay is that under appropriate import reaction conditions, peroxisomes will accumulate biotin in the form of biotinylated luciferase. At the conclusion of the reaction, the cells are lysed, and the amount of biotin is quantitated by an enzyme-linked immunosorbent assay (ELISA) using streptavidin labeled with horseradish peroxidase.

\section{MATERIALS AND METHODS}

Luciferase biotinylation. Firefly (Photinus pyralis) luciferase from Sigma (St. Louis, MO) was biotinylated essentially as described by Schmid and Carter [22]. Briefly, 2 mg of luciferase was dissolved in $200 \mu \mathrm{l}$ PBS and incubated with $20 \mu \mathrm{l}$ of $8.2 \mathrm{mM} \mathrm{6-((6-((bioti-}$ noyl)amino)hexanoyl)amino)hexanoic acid, succinimidyl ester (biotin-XX SE) (Molecular Probes, Eugene, OR) in DMSO for $45 \mathrm{~min}$ at room temperature. Biotinylated luciferase was separated from unconjugated biotin-XX SE by gel filtration using a G25 spin- desalt column preequilibrated with PBS/0.2\% bovine serum al bumin (BSA).

SDS-PAGE/blotting. Proteins were separated by SDS-PAGE, transferred to nitrocellulose, and blotted with antibodies or streptavidin alkaline phosphatase as described previously [21]. Anti-SKL, anti-luciferase, and streptavidin alkaline-phosphatase were all used at a dilution of 1:5000.

Measurement of cytosolic and peroxisomal markers. Lactate dehydrogenase activity was determined as described by Storrie and Madden [23]. Hsc70 levels were quantitated by Western blotting with the monoclonal antibody 13D3 as described by Terlecky et al. [24].

ELISA-based import assay. Peroxisomal PTS1-protein import was reconstituted using a system based on a previously described assay for receptor-mediated endocytosis in semi-intact cells [25]. The assay will be described briefly here, noting relevant differences with the original description. The plasma membranes of human epidermoid carcinoma (A431) cells or diploid lung fibroblasts (I MR90) were permeabilized by mechanical disruption, a procedure which permits $87-92 \%$ of the cytosol to be removed (Fig. 4A) while affording com- 
plete access to the intact ( $>90 \%$ catalase latency, data not shown) intracellular organelles. After the cells were pelleted and resuspended at $4^{\circ} \mathrm{C}$, they were incubated with the biotinylated substrate (the PTS1-containing enzyme, luciferase, typically at 6-12 $\mu \mathrm{g} / \mathrm{ml}$ ) at $37^{\circ} \mathrm{C}$ in a $40-\mu \mathrm{l}$ reaction volume. The import reaction buffer (IRB) contained $40 \mathrm{mM} \mathrm{N}$-2-hydroxyethylpiperazine-N'-2-ethanesulfonic acid (Hepes)-sodium hydroxide (pH 7.4), $85 \mathrm{mM}$ sucrose, $2 \mathrm{mM}$ magnesium acetate, $100 \mathrm{mM}$ potassium acetate, $100 \mu \mathrm{M}$ zinc chloride, $1 \mathrm{mM}$ adenosine $5^{\prime}$-triphosphate, $5 \mathrm{mM}$ creatine phosphate, and 0.4 IU creatine phosphokinase. After $45 \mathrm{~min}$, the level of import was determined by masking accessible biotin sites with avidin (Calbiochem, La J olla, CA), quenching excess avidin with biocytin (Calbiochem), and solubilizing the cells with detergent. The concentrations of avidin and biocytin in the masking/quenching reactions were increased by $50 \%$ over those originally described. One hundred microliters of the cell lysates were plated on microtiter plates coated with anti-luciferase antibodies. (Rabbit anti-luciferase antibodies were used at a 1:500 dilution.) The extent of unmasked biotin, the hallmark of import, was then quantitated with horseradish peroxidase-labeled streptavidin in a microplate absorbance reader set at $490 \mathrm{~nm}$ and corrected for background at $650 \mathrm{~nm}$. The maximal absorbance signal obtained in a given experiment depended on such factors as the concentration of ligand added and the number of cells used (typically 1.4-2.7 $\times 10^{5}$ per reaction).

Cytosol was prepared from CHO cells as described by Smythe et al. [25] except that a Dounce homogenizer was used to disrupt the cells. Anti-Pex $2 p$ antibodies were provided by Dr. Rolf Thieringer of Merck.

For the biochemical analysis of protein import into organelle pellets, the import and masking/quenching reactions were scaled up sixfold. I mport reactions were conducted with (CHO) cytosol added. After a $45-\mathrm{min}$ incubation at $37^{\circ} \mathrm{C}$, the A431 cells were pelleted and masked/quenched with a $(6 \times)$ avidin and biocytin reaction as outlined above except that the buffer was $0.25 \mathrm{M}$ sucrose, $10 \mathrm{mM}$ triethanolamine (pH 7.8), $10 \mathrm{mM}$ acetic acid, $1 \mathrm{mM}$ EDTA, and $0.1 \%$ $\mathrm{EtOH}$. After quenching, the cells were homogenized on ice with 10 strokes of a Teflon homogenizer, followed by 10 strokes of a tightfitting Dounce homogenizer. The resultant homogenate was centrifuged at $1000 \mathrm{~g}$ to remove nuclei and unbroken cells and then at $17,000 \mathrm{~g}$ to create the organelle pellet. Proteins in the organelle pellet were separated by SDS-PAGE, transferred to nitrocellulose, and probed with streptavidin alkaline-phosphatase. Alternatively, the level of unmasked biotinylated luciferase in the organelle pellets was determined by ELISA as described above.

Immunofluorescence-based import assay. A431 cells were permeabilized with $0.05 \mathrm{U} / \mathrm{ml}$ streptolysin-O and incubated with $60 \mu \mathrm{g} / \mathrm{ml}$ biotinylated luciferase for $45 \mathrm{~min}$ at $37^{\circ} \mathrm{C}$ in an in vitro import assay essentially as described by Wendland and Subramani [20]. The import system was optimized for use with A431 cells as follows. Permeabilization and import reaction volumes were $60 \mu \mathrm{l}$ and the buffer contained $20 \mathrm{mM}$ Hepes-potassium hydroxide (pH 7.3), $2 \mathrm{mM}$ magnesium acetate, $110 \mathrm{mM}$ potassium acetate, $5 \mathrm{mM}$ sodium acetate, $100 \mu \mathrm{M}$ zinc chloride, $2 \mathrm{mM}$ dithiothreitol, $1 \mathrm{mM}$ ethylene glycolbis( $\beta$-aminoethyl ether)- $\mathrm{N}, \mathrm{N}, \mathrm{N}^{\prime}, \mathrm{N}^{\prime}$-tetraacetic acid, $1 \mathrm{mM}$ adenosine $5^{\prime}$-triphosphate, $5 \mathrm{mM}$ creatine phosphate, and $20 \mathrm{U} / \mathrm{ml}$ creatine phosphokinase. Import was evaluated by indirect immunofluorescence using guinea pig anti-luciferase antibodies at a 1:250 dilution or by indirect fluorescence using FITC-labeled avidin at a 1:25 dilution. The cells were blocked in 4\% BSA in PBS for $1 \mathrm{~h}$ before incubation with primary antibodies or avidin. Masking/quenching of the unimported biotinylated luciferase was accomplished as for the ELISA-based assay above. Guinea pig antibodies were detected with FITC-labeled, goat anti-guinea pig IgG at a 1:25 dilution. For colocalization studies, peroxisomes were identified with rabbit antiPMP70 antibody at a 1:250 dilution and the antibody was detected by CY3-conjugated, goat anti-rabbit IgG at a 1:300 dilution. Importantly, in these experiments no FITC signal was detected in the

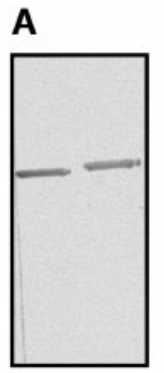

L BL

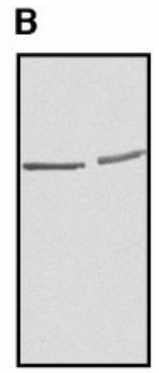

L BL

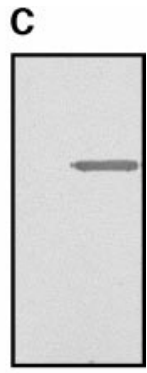

L BL
FIG. 1. Biotinylation of luciferase. Biotin was chemically coupled to luciferase as described under Materials and Methods. $250 \mathrm{ng}$ of luciferase (L) and biotinylated luciferase (BL) was separated by SDS-PAGE, transferred to nitrocellulose, and probed with (A) antiluciferase antibodies, (B) anti-SKL antibodies, and (C) streptavidin alkaline-phosphatase.

543-nm ("red") channel, and no CY3 signal was detected in the 488-nm ("green") channel (data not shown). All fluorescence reagents were from KPL (Gaithersburg, MD). Rabbit anti-SKL antibody was used at a dilution of 1:250. Slowfade antifade from Molecular Probes was used as the mounting medium. Microscopy was performed on a Zeiss LSM-310 confocal microscope at the Wayne State University School of Medicine Molecular \& Cellular Imaging and Analytical Cytometry Core Facility.

\section{RESULTS}

\section{Quantitative Analysis of PTS1 Protein I mport in Vitro}

To further elucidate the molecular mechanisms of peroxisomal protein import, and identify the requisite biochemical components, we developed a quantitative in vitro assay for peroxisomal PTS1-protein import. This assay, based on a similar system for examining coated-pit assembly, invagination, and coated-vesicle formation [25], is ELISA based and utilizes semipermeabilized human A431 cells or fibroblasts and a biotinylated PTS1-containing reporter protein. The ligand we chose to biotinylate was the well-characterized, PTS1-containing protein luciferase [7, 26]. Biotinylation results in a conjugate protein that is recognized by anti-luciferase antibodies and anti-SKL antibodies, as well as by streptavidin alkaline-phosphatase (Fig. 1). This latter recognition confirms the presence of the biotin moiety in the conjugate protein. Also, biotinylated luciferase is recognized by the PTS1-import receptor, Pex5p, to the same extent as its unmodified counterpart in an in vitro binding assay (data not shown).

After biotinylation, and optimization of conditions to trap the molecule in wells of an ELISA plate coated with anti-luciferase antibodies (data not shown), internalization assays were performed. Levels of import were determined as follows: after internalization into peroxisomes, the biotin groups on unimported biotinylated luciferase were sequestered with avidin, and the 


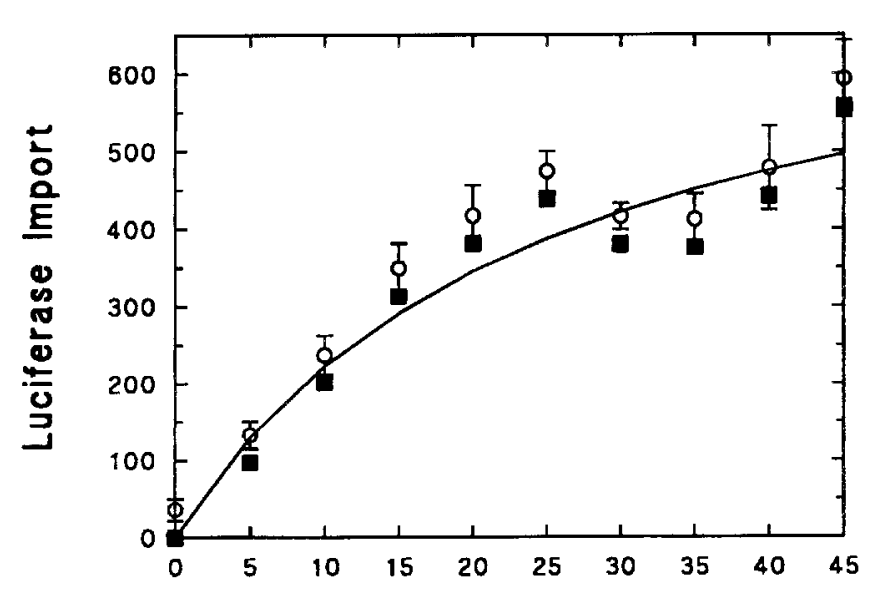

Time (min)

FIG. 2. Peroxisomal import kinetics. Semi-intact $A 431$ cells were incubated at $37^{\circ} \mathrm{C}$ with biotinylated luciferase in the in vitro import reaction described under Materials and Methods. At the times indicated, the extent of import was determined by ELISA. (O) The raw absorbance units $\left(\times 10^{3}\right)$ obtained at each time point; $(\square)$ and accompanying solid line indicate the adjusted values reflecting subtraction of the time 0 value from all others. Results shown are means \pm 1 standard deviation of triplicate samples.

excess avidin bound to biocytin. These reagents cannot penetrate the peroxisome membrane. The biotinylated luciferase was released from cells by treatment with detergent and was captured in microtiter wells using anti-Iuciferase antibodies, and the biotin groups remaining on the biotinylated luciferase corresponding to the imported substrate were quantitated with a streptavidin horseradish peroxidase conjugate. Using the accumulation of avidin-inaccessible biotinylated luciferase as the hallmark of import, peroxisomal import in human A431 cells was found to be time- (Figs. 2, 4B, and 5) and temperature- (F igs. 3 and 4B) dependent. Importantly, no import of biotinylated ovalbumin, a non-PTS1-containing protein, was observed (data not shown).

The peroxisome membrane contains at least three proteins, Pex $2 p$, Pex10p, and Pex $12 p$, which contain zinc-binding signature sequences [14]. To examine whether zinc or other metal ions play a role in the import of biotinylated luciferase, we tested their effect in our assay. Low concentrations $(100 \mu \mathrm{M})$ of zinc (Fig. 3), but not other divalent ions (e.g., calcium-data not shown), stimulated import some sixfold. This zinc effect was largely reversed by the divalent metal chelator 1,10-phenanthroline (Fig. 3). We also examined the effect of including anti-Pex2p antibodies in the import reaction. As shown in Fig. 3, these antibodies inhibited the assay, directly implicating the peroxin in PTS1 import. Similar effects of anti-Pex2p antibodies were observed in the immunofluorescence-based import assay described below; control antibodies did not affect import in these assays (data not shown). Unfortunately, we do not yet have antibodies to Pex10p or Pex12p, so their involvement could not be tested in this manner.

The in vitro assay was applied to other cells to examine their import capacities (Fig. 3). Normal human (I MR90) fibroblasts imported bi otinylated luciferase to approximately the same level ( $\sim 85 \%)$ as seen in A431 cells. In contrast, fibroblasts from patients with the fatal peroxisomal disorder cerebrohepatorenal (Zellweger) syndrome were incapable of importing significant amounts of biotinylated luciferase ( $\sim 4 \%$ of the A431 level). The cell line, called FAIR-T, is known to lack the PTS1 receptor, Pex5p [21, 27].

\section{Cytosol Stimulation of Import}

During preparation of semi-intact cells for the in vitro import assay, a $15-\mathrm{min}$ incubation at $4^{\circ} \mathrm{C}$ was included to allow leakage of cytosolic components. This process resulted in $92 \%$ of the cytosolic marker LDH and $87 \%$ of the cytosolic Hsc70 molecule to be released (Fig. 4A). Clearly, the 8-13\% of cytosol that remains was capable of supporting import (Figs. 2 and 3). How-
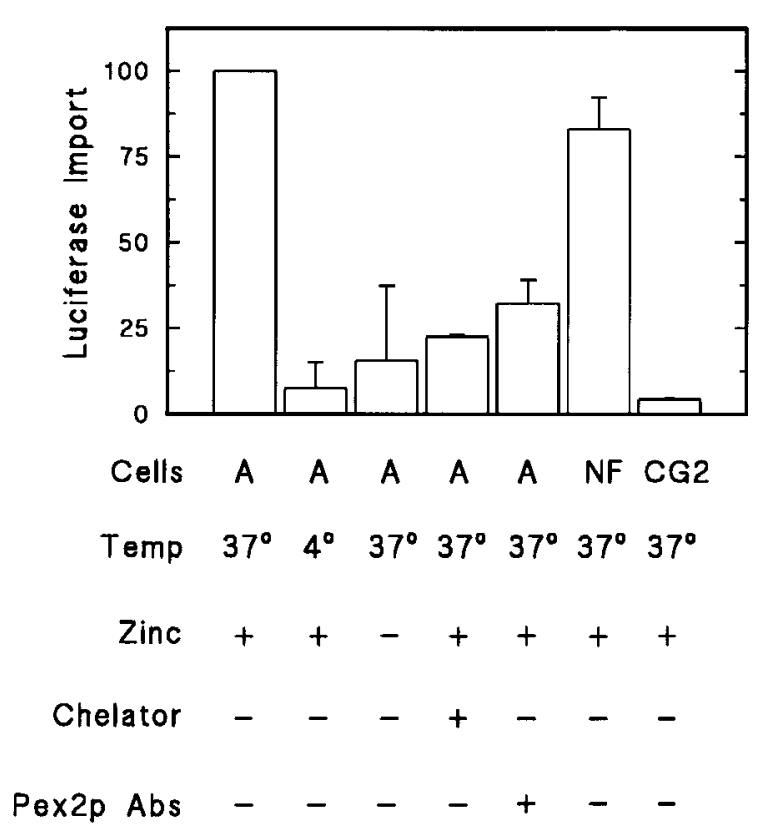

FIG. 3. Peroxisomal protein import. Semi-intact A431s (A), normal human IMR90 fibroblasts (NF), or fibroblasts from a Zellweger syndrome patient of complementation group 2 (CG2) were incubated at $37^{\circ} \mathrm{C}$ or at $4^{\circ} \mathrm{C}$ with biotinylated luciferase in the in vitro import reaction described under Materials and Methods. After $45 \mathrm{~min}$, import was quantitated by ELISA. Where indicated, zinc chloride was omitted from the IRB or the ion chelator 1,10-phenanthroline (1 mM final concentration) or anti-Pex $2 p$ antibodies (5 $\mu \mathrm{l}$ ) were added. Results presented (means \pm 1 standard deviation) are a composite of nine separate experiments and normalized to the level of import in A431 cells (which is arbitrarily set at 100 ) to permit comparison. 
A

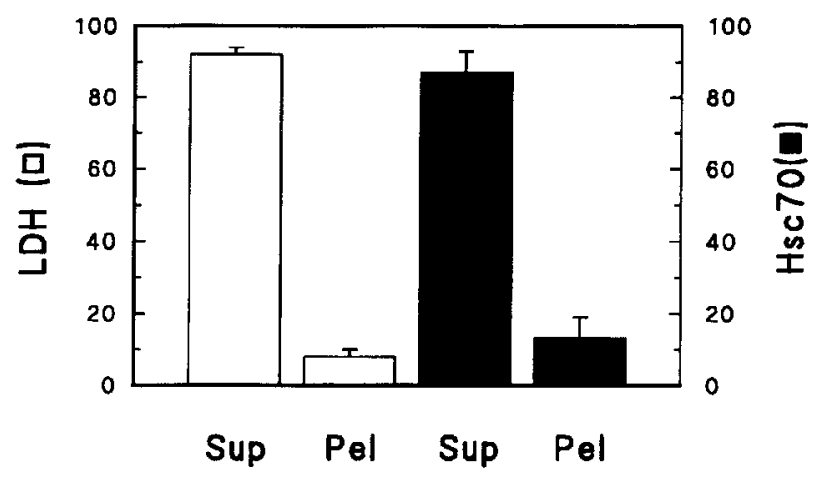

B

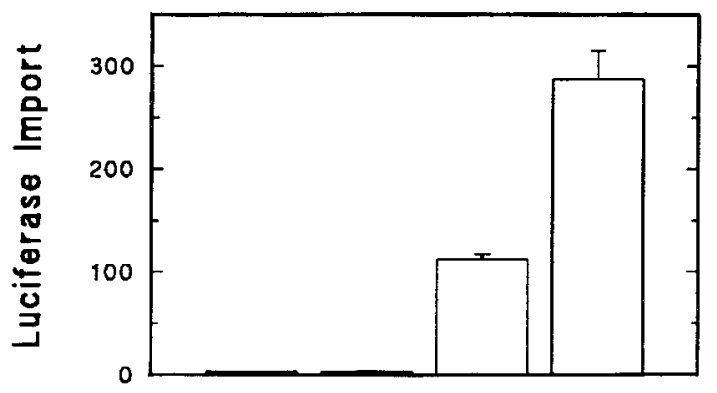

$\begin{array}{rrrrr}\text { Time }(\text { min) } & 0 & 45 & 45 & 45 \\ \text { Temp } & - & 4^{\circ} & 37^{\circ} & 37^{\circ} \\ \text { Cytosol } & - & - & - & +\end{array}$

FIG. 4. (A) Cytosol leakage from permeabilized cells. Semi-intact A431 cells were prepared as described under Materials and Methods. After $15 \mathrm{~min}$ at $4^{\circ} \mathrm{C}$, the cells were pelleted and the resultant supernatants (Sup) and pellets (Pel) analyzed for the relative amounts of the cytosolic markers lactate dehydrogenase (LDH) and Hsc70. The total LDH or Hsc70 present in the supernatant and pellet fractions was arbitrarily set at 100. (B) Cytosol stimulation of peroxisomal import. Semi-intact A431 cells were incubated with biotinylated luciferase in the in vitro import reaction described under Materials and Methods. Where indicated, $\mathrm{CHO}$ cytosol was added at a concentration of $10 \mu \mathrm{g} / \mathrm{ml}$. After $45 \mathrm{~min}$, import was quantitated by ELISA and the results (means and ranges $\left(\times 10^{3}\right)$ of duplicate samples) are presented as absorbance units minus the time 0 (40 absorbance units) value.

ever, this did not represent maximum levels of import since the addition of exogenous ( $\mathrm{CHO}$ ) cytosol was stimulatory (Fig. 4B). Most cytosol preparations resulted in similar two- to threefold stimulations of import although some were more active (data not shown). The basis of these differences remains to be elucidated.

\section{Biotinylated Luciferase in Organelle \\ Pellets/ Peroxisomes}

To confirm that biotinylated luciferase was imported into peroxisomes, we scaled up the reaction sixfold and, after the import and masking/quenching steps, homogenized the cells and prepared organelle pellets. As shown in Fig. 5, there was a time-dependent accumulation of biotinylated luciferase in organelle pellets, as assayed by both blotting with streptavidin alkalinephosphatase and ELISA. To determine whether the organellar biotinylated luciferase was associated with peroxisomes, we resuspended the organelle pellets after a 45-min import reaction and used a N ycodenz step gradient to fractionate the sample. Catalase and imported biotinylated luciferase largely comigrated in these gradients (data not shown), suggesting that biotinylated luciferase was targeted to peroxisomes in the in vitro assay.

\section{Analysis of Biotinylated Luciferase I mport \\ by Confocal Fluorescence Microscopy}

To demonstrate more directly that biotinylated luciferase was imported into peroxisomes, we localized the import substrate using indirect confocal fluorescence microscopy (Figs. 6-8). The mechanical disruption technique employed to permeabilize cells for the in vitro assay required them to be lifted from the culture plate or coverslips and therefore was incompatible with morphological analyses. To circumvent this problem, we used the plasma membrane-specific permeabilization agent streptolysin-O to create semi-intact cells. This treatment permitted the execution of an import reaction, followed by the localization of biotinylated luciferase and peroxisomes in situ.

We performed an import and masking/quenching reaction with streptolysin-O-treated A431 cells and visualized the imported biotinylated luciferase using guinea pig anti-luciferase antibodies and a FITC-labeled, goat anti-guinea pig, secondary antibody (Fig. $6 \mathrm{~A})$. The substrate protein appeared in punctate structures, randomly scattered through the cytoplasm. In the same cells, peroxisomes were identified using rabbit antibodies to the peroxisomal membrane protein, PMP70, and appropriate CY3-labeled secondary antibodies (Fig. 6B). A punctate staining pattern was obtained again, and confocal superimposition of the images (Fig. 6C) revealed that the imported substrate colocalized virtually completely with peroxisomes.

Colocalization of imported biotinylated luciferase and peroxisomes was also accomplished using avidinFITC to recognize the biotinylated import substrate (Fig. 7A). In control experiments, no staining was obtained if the import reaction was conducted without an ATP-regenerating system (Fig. 7C) or without luciferase (Fig. 7D). Since the biotin groups on unimported biotinylated luciferase were masked/quenched, the import signal obtained presumably reflects bona fide import into the peroxisome and not binding to the surface 
A

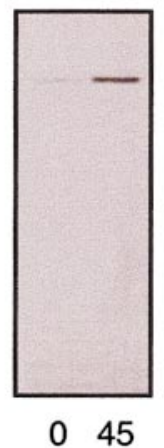

5 Time
B

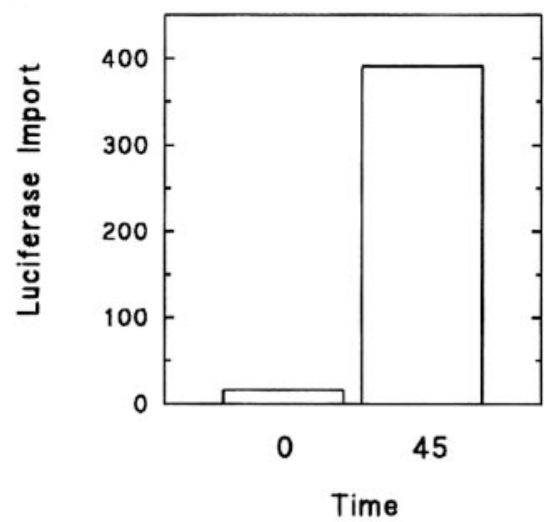

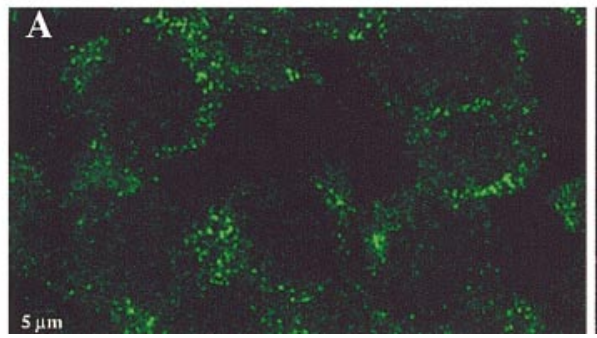
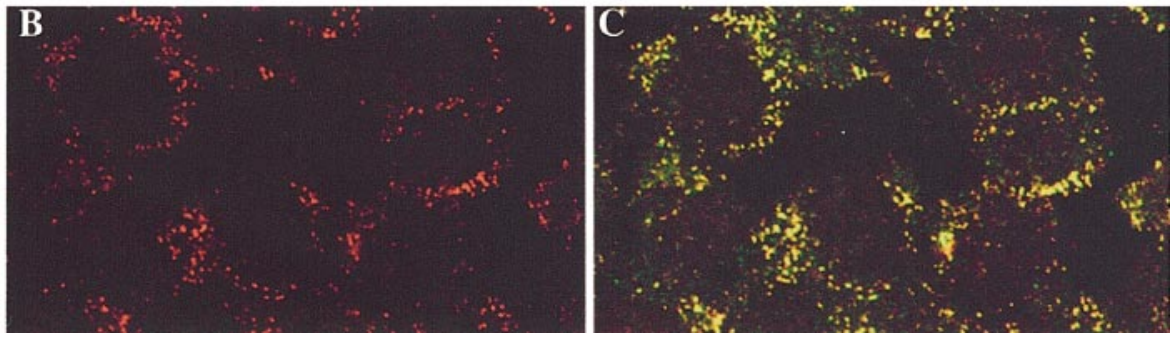

FIG. 5. Biotinylated luciferase in organelle pellets. Semi-intact A431 cells were incubated at $37^{\circ} \mathrm{C}$ in a sixfold scaled up in vitro import reaction as indicated. After a 45-min incubation, the cells were pelleted and homogenized, and an (organelle) pellet fraction was prepared as described under Materials and Methods. In (A), equivalent portions of the proteins in the organelle pellet fraction were separated by SDS-PAGE, transferred to nitrocellulose, and probed with streptavidin alkaline-phosphatase. In (B), the level of biotinylated luciferase import in equivalent portions of the organelle pellets was determined by ELISA. Values presented are absorbance units ( $\times 10^{3}$ ).

FIG. 6. Biotinylated luciferase is imported into peroxisomes. Streptolysin-O-permeabilized A431 cells were incubated with $60 \mu \mathrm{g} / \mathrm{ml}$ (biotinylated) luciferase for $45 \mathrm{~min}$ at $37^{\circ} \mathrm{C}$ as described under Materials and Methods. The cells were then fixed, detergent-treated, and examined by indirect immunofluorescence. Cells were incubated simultaneously with guinea pig anti-luciferase antibody followed by an FITC-conjugated secondary antibody and a rabbit anti-PMP70 antibody followed by a CY 3-conjugated secondary antibody. Biotinylated luciferase is revealed in green (A) and PMP70 is revealed in red (B). In (C), confocal superimposition of the images reveals col ocalized proteins which register as yellow/orange.

of the organelle. Confirmation of true import of the substrate was also accomplished by examining the staining patterns of peroxisomal antigens in cells permeabilized with streptolysin-O, fixed, and treated or not with the detergent Triton X-100 prior to immunostaining (Fig. 8). PMP70, a cytosolically exposed, peroxisomal membrane protein, was recognized by appropriate antibodies in the absence of detergent treatment (Fig. 8A). In contrast, neither SKL-containing proteins nor imported biotinylated luciferase was recognized by appropriate antibodies in a similar incubation (Figs. $8 \mathrm{~B}$ and $8 \mathrm{C})$. If, however, the cells were treated with detergent, both SKL-containing proteins and imported biotinylated luciferase were visible (Figs. 8D and 8E).

\section{DISCUSSION}

In this report, we describe a reliable quantitative in vitro assay for peroxisomal import of PTS1-containing proteins. This ELISA-based assay employs semi perme- abilized human cells and a biotinylated import substrate. It faithfully recapitulates several well-defined properties of peroxisomal protein import and offers several advantages over previously described import systems. The assay should make possible, for the first time, a rapid and large-scale analysis of the necessary biochemical components and underlying molecular mechanisms of import.

An immunofluorescence-based assay, also utilizing semipermeabilized cells, is an effective system that has led to the description of several novel properties of the import process [20]. Indeed, a variation of it is used in this study (Figs. 6- 8) to confirm that the PTS1 import substrate has correctly entered peroxisomes. However, a major drawback with the system is the time-consuming nature of the requisite microscopy. In contrast, the ELISA-based assay described herein permits the processing of many samples within a single experiment.

An important parameter regarding the assay is the 


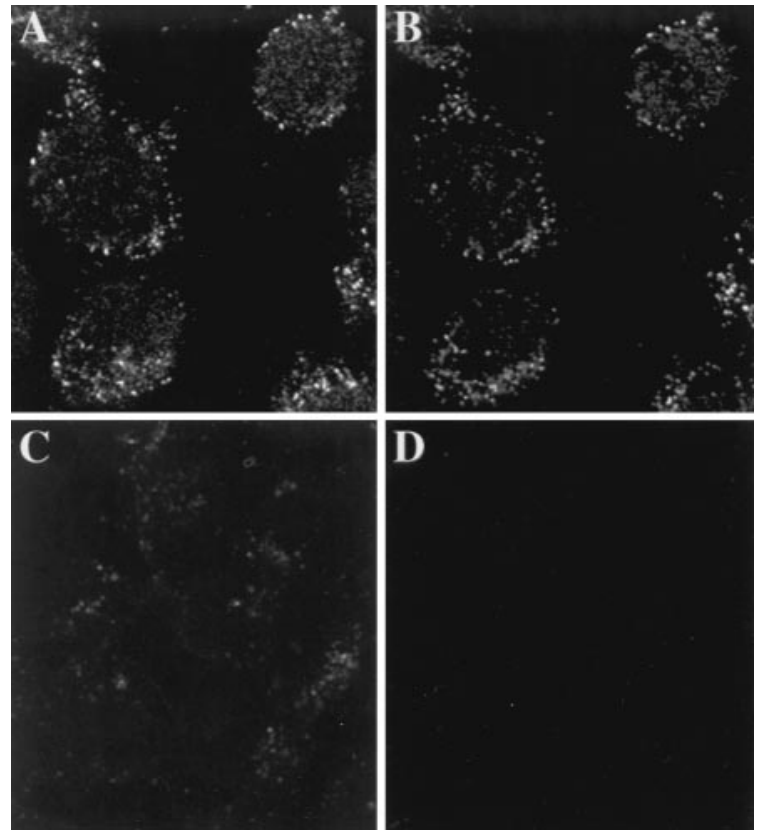

FIG. 7. Recognition of imported biotinylated luciferase by avidin. Streptolysin-O-permeabilized A431 cells were incubated with biotinylated luciferase as described for Fig. 6 . After $45 \mathrm{~min}$ at $37^{\circ} \mathrm{C}$, the biotin moiety of unimported biotinylated luciferase was masked/ quenched with avidin and biocytin as described under Materials and Methods. The cells were then fixed, detergent-treated, and examined by indirect fluorescence or by indirect immunofluorescence. Cells were treated simultaneously with FITC-avidin and an anti-PMP70 antibody followed by a CY3-conjugated secondary antibody. Biotinylated luciferase is shown in (A) and PMP70 is shown in (B). The in vitro import reaction with biotin masking/quenching was conducted in buffer without ATP or an ATP-regenerating system in (C) or in buffer without biotinylated luciferase in (D). The cells were fixed, detergent-treated, incubated with FITC-avidin, and processed for indirect fluorescence.

signal-to-noise ratio. That is, how much of the signal observed at a particular time point is present at time 0 . In the experiment shown in Fig. 2, the signal was quite high (>95\%). Although this property does vary ( $75 \%$ in the experiment shown in Fig. 4B, for example), overall throughout the many experiments conducted, the signal/noise ratio remained high.

To ensure that the signal being measured truly represents protein import into the peroxisome, a series of biochemical and morphological assays was performed. The first approach involved showing that biotinylated luciferase accumulated in organelle pellets after the import reaction (Fig. 5). As these were crude organelle pellets, a Nycodenz step gradient was used to further illustrate the colocalization of imported biotinylated luciferase and peroxisomes. However, since other organelle marker enzymes were not examined in this assay, it remained a formal, al beit unlikely, possibility that biotinylated luciferase was present in another organelle.
To address this, a more detailed morphological analysis was initiated. Since the necessary confocal fluorescence microscopy could be performed only on immobilized cells, mechanical disruption was not possible. Therefore, we employed streptolysin-O to permeabilize cells-in essence, we were performing the immunofluorescence-based import assay described by Wendland and Subramani [20]. Using this approach, for the first time with human A431 cells, it was clear that biotinylated luciferase was taken up into the lumen of peroxisomes (Figs. 6-8).

As part of the ELISA-based import assay's characterization, we evaluated the kinetics of peroxisomal import (Fig. 2). Import appeared to peak at approximately 45 min-roughly consistent with the time course results obtained with other import assays. That is, Wendland and Subramani [20], using the immunofluorescence-based import assay, and Walton et al . [4], using the microinjection-based import assay, observed maximal import at $1 \mathrm{~h}$; Imanaka et al. [16], using purified rat liver peroxisomes, observed a plateau at approximately $30 \mathrm{~min}$.

All assays are in accord that peroxisomes do not import substrates at low temperatures $([16,18,20]$, Figs. 3 and 4B). Furthermore, since previous work showed ATP hydrolysis to be necessary for import, ATP and an ATP-regenerating system were routinely included in all import reaction buffers used in this study. If these components were left out of the incubation, and endogenous ATP suitably depleted, import was significantly reduced (data not shown). Similar effects of the absence of ATP were observed in the immunofluorescence-based assay (Fig. 7).

A powerful aspect of the ELISA-based assay is that it can be applied to more than one human cell type. As shown in Fig. 3, import into peroxisomes of normal fibroblasts was highly efficient. This contrasted with cells of patients with the peroxisomal disorder Zellweger syndrome, which imported little, if any, substrate (Fig. 3). Perhaps in future studies, this assay could be used to add back the biochemical components defective or missing in specific patient cell lines. The only caveat is that the defect must lie in a cytosolic molecule, as there would be no way to correctly introduce a membrane protein back into cells or peroxisomes.

Previous assays have been equivocal with respect to the effects of cytosol. I n vitro assays employing purified peroxisomes suggest no effect of cytosol [16], whereas the immunofluorescence-based, semipermeabilized system has been shown to require cytosol [20] as well as to be cytosol-independent [28]. Since a number of peroxins and chaperone molecules are cytosolic [14, 29], it is reasonable that cytosolic factors are necessary.

Our results indicate a clear stimulatory effect of 

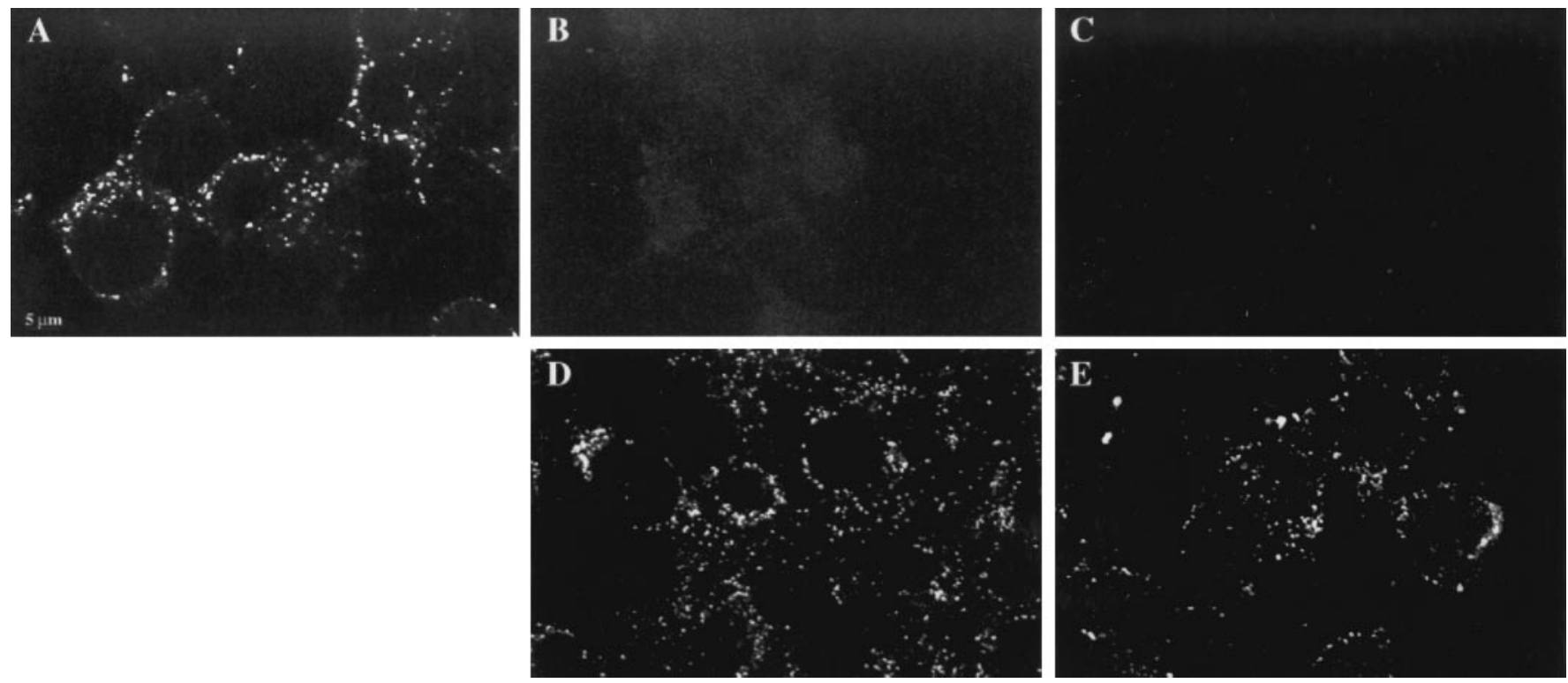

FIG. 8. Biotinylated luciferase is imported into the peroxisomal matrix. In (A-E), semipermeabilized A431 cells were incubated with biotinylated luciferase as described for Fig. 6. After masking/quenching of unimported biotinylated luciferase with avidin and biocytin, the cells were fixed, detergent-treated ( $D$ and $E)$, or not (A, B, and C), and examined by indirect immunofluorescence or by indirect fluorescence. Cells were incubated with anti-PMP70 antisera in (A), with anti-SKL antisera in (B) and (D), and with FITC-avidin in (C) and (E). Where appropriate, species-specific antiserum was used to visualize the bound primary antibodies.

exogenously added cytosol (Fig. 4B). A two- to threefold stimulation by cytosol was typically observed; however, as pointed out above, this effect is variable, with some preparations stimulating over sevenfold. The basis of these activity differences is unclear - it may reflect differential leakage of endogenous factors, although cells used in the in vitro import assays are treated exactly the same between experiments, or some undefined properties of the cytosol itself. One possibility is that during cytosol preparation, homogenization results in variable leakage of proteases or other inhibitors from disrupted lysosomes and other organelles. Perhaps these organelle contents adversely affect the activity of requisite components. Also, it should be noted that we have not yet been able to develop a cocktail of peroxins, chaperones, and other molecules which will stimulate import to the same level as whole cytosol. Clearly, all the necessary components, or the means to maintain their activities, have not been identified.

A novel aspect of peroxisomal protein import re vealed by the E LISA-based assay was the effect of zinc. A clear stimulatory effect was realized at a concentration of $100 \mu \mathrm{M}$ (Fig. 3). I mportantly, other ions present at similar concentrations show no such stimulation and furthermore, the zinc effect was largely eliminated by the cation chelator 1,10-phenanthroline (Fig. 3). These exciting observations suggest that peroxisomal protein import may be regulated in a manner heretofore not envisioned.
Zinc is critically important in a vast array of biochemical and metabolic processes [30]. The intracellular concentration of zinc has been cal culated to be some 400 to $800 \mu \mathrm{M}$ [31, 32], although it is not well understood how the cell stores and traffics the ion to appropriate sites. As pointed out above, the peroxisome membrane contains at least three zinc-finger-containing peroxins. Our results directly implicate one of them, specifically Pex $2 p$, in the import of PTS1-containing proteins (Fig. 3). Perhaps zinc regulates the activity of Pex $2 p$ or, indeed, other peroxins; further analysis of the role of zinc in PTS1-protein import is currently under way. Interestingly, the import of certain (carrier) proteins into mitochondria also requires $100 \mu \mathrm{M}$ zinc and is mediated by two zinc-binding (mitochondrial) membrane proteins-Tim10 and Tim12 [33].

We gratefully acknowledge Dr. Sandra L. Schmid and Laura J . Terlecky of the Departments of Cell and Molecular Biology at the Scripps Research Institute, La J olla, California, for technical advice in the development of the import assay, as well as for allowing us to perform pilot studies in their laboratory. We thank Linda Mayernik and Dr. Kamiar Moin of the Wayne State University School of Medicine Molecular \& Cellular Imaging and Analytical Cytometry Core Facility for their help in the immunofluorescence work. We also acknowledge the Center for Molecular and Cellular Toxicology with Human Applications in Michigan (funded by NIEHS Grant 1 P30 ES06639). This work was supported by grants from the Children's Research Center of Michigan (99-M-17), the March of Dimes Birth Defects Foundation (5-FY99-843), and the NIH (DK56299) to S.R.T. 
and by grants from the NIH (DK41737) and the March of Dimes Birth Defects Foundation (1-FY99-611) to S.S.

\section{REFERENCES}

1. Walton, P. A., Hill, P. E., and Subramani, S. (1995). Import of stably folded proteins into peroxisomes. Mol. Biol. Cell. 6, 675683.

2. Glover, J. R., Andrews, D. W., and Rachubinski, R. A. (1994). Saccharomyces cerevisiae peroxisomal thiolase is imported as a dimer. Proc. Natl. Acad. Sci. USA 91, 10541-10545.

3. McNew, J . A., and Goodman, J . M. (1994). An oligomeric protein is imported into peroxisomes in vivo. J . Cell Biol. 127, 1245-1257.

4. Walton, P. A., Wendland, M., Subramani, S., Rachubinski, R. A., and Welch, W. J . (1994). I nvolvement of 70-kD heat-shock proteins in peroxisomal import. J . Cell Biol. 125, 1037-1046.

5. Crookes, W. J ., and Olsen, L. J . (1998). The effects of chaperones and the influence of protein assembly on peroxisomal protein import. J . Biol. Chem. 273, 17236-17242.

6. Hettema, E. H., Ruigrok, C. C. M., Koerkamp, M. G., van den Berg, M., Tabak, H. F., Distel, B., and Braakman, I. (1998). The cytosolic DnaJ -like protein Djplp is involved specifically in peroxisomal protein import. J . Cell Biol. 142, 421- 434.

7. Gould, S. J., Keller, G. A., Hosken, N., Wilkinson, J., and Subramani, S. (1989). A conserved tripeptide sorts proteins to peroxisomes. J . Cell Biol. 108, 1657-1664.

8. Terlecky, S. R., Nuttley, W. M., McCollum, D., Sock, E., and Subramani, S. (1995). The Pichia pastoris peroxisomal protein PAS8p is the receptor for the C-terminal tripeptide peroxisomal targeting signal. EMBO J . 14, 3627-3634.

9. Dodt, G., and Gould, S. J. (1996). Multiple PEX genes are required for proper subcellular distribution and stability of Pex5, the PTS1 receptor: Evidence that PTS1 protein import is mediated by a cycling receptor. J . Cell Biol. 135, 1763-1774.

10. Gould, S. J ., Kalish, J . E., Morell, J . C., Bjorkman, J ., Urquhart, A. J ., and Crane, D. I. (1996). An SH3 protein in the peroxisomal membrane is a docking factor for the PTS1 receptor. J . Cell Biol. 135, 85-95.

11. Fransen, M., Terlecky, S. R., and Subramani, S. (1998). Identification of a human PTS1 receptor docking protein directly required for peroxisomal protein import. Proc. Natl. Acad. Sci. USA 95, 8087- 8092.

12. Lazarow, P. B., and Moser, H. W. (1989). Disorders of peroxisome biogenesis. In "The Metabolic Basis of I nherited Disease" (A. L. Beaudet, C. R. Scriver, W. S. Sly, and D. Valle, Eds.), 6th ed., McGraw-Hill, New York.

13. Wiemer, E. A., and Subramani, S. (1994). Protein import deficiencies in human peroxisomal disorders. Mol. Genet. Med. 4, 119-152.

14. Terlecky, S. R., and Fransen, M. (2000). How peroxisomes arise. Traffic 1, 465- 473.

15. Subramani, S. (1998). Components involved in peroxisome import, biogenesis, proliferation, turnover, and movement. Physiol. Rev. 78, 171-188.

16. Imanaka, T., Small, G. M., and Lazarow, P. B. (1987). Translocation of acyl-CoA oxidase into peroxisomes requires ATP hydrolysis but not a membrane potential. J. Cell Biol. 105, 2915-2922.

Received August 28, 2000

Revised version received November 8, 2000

Published online J anuary 3, 2001
17. Thieringer, R., Shio, H., Han, Y. S., Cohen, G., and Lazarow, P. B. (1991). Peroxisomes in Saccharomyces cerevisiae: I mmunofluorescence analysis and import of catalase A into isolated peroxisomes. Mol. Cell Biol. 11, 510-522.

18. Walton, P. A., Gould, S. J ., Feramisco, J . R., and Subramani, S. (1992). Transport of microinjected proteins into peroxisomes of mammalian cells: Inability of Zellweger cell lines to import proteins with the SKL tripeptide peroxisomal targeting signal. Mol. Cell. Biol. 12, 531-541.

19. Hill, P. E., and Walton, P. A. (1995). Import of microinjected proteins bearing the $S K L$ peroxisomal targeting sequence into the peroxisomes of a human fibroblast cell line: Evidence that virtually all peroxisomes are import-competent. J . Cell Sci. 108, 1469-1476.

20. Wendland, M., and Subramani, S. (1993). Cytosol-dependent peroxisomal protein import in a permeabilized cell system. J . Cell Biol. 120, 675- 685.

21. Wiemer, E. A., Nuttley, W. M., Bertolaet, B. L., Li, X., Francke, U., Wheelock, M. J ., Anne, U. K., J ohnson, K. R., and Subramani, S. (1995). Human peroxisomal targeting signal-1 receptor restores peroxisomal protein import in cells from patients with fatal peroxisomal disorders. J . Cell Biol. 130, 51- 65.

22. Schmid, S. L., and Carter, L. L. (1990). ATP is required for receptor-mediated endocytosis in intact cells. J . Cell Biol. 111, 2307-2318.

23. Storrie, B., and Madden, E. A. (1990). I solation of subcellular organelles. Methods Enzymol. 182, 203-225.

24. Terlecky, S. R., Chiang, H. L., Olson, T. S., and Dice, J. F. (1992). Protein and peptide binding and stimulation of in vitro Iysosomal proteolysis by the 73-kDa heat shock cognate protein. J. Biol. Chem. 267, 9202-9209.

25. Smythe, E., Redelmeir, T. E., and Schmid, S. L. (1992). Receptor-mediated endocytosis in semiintact cells. Methods Enzymol. 219, 223-234.

26. Gould, S. J ., Keller, G., and Subramani, S. (1987). Identification of a peroxisomal targeting signal at the carboxy terminus of firefly luciferase. J . Cell Biol. 105, 2923-2931.

27. Dodt, G., Braverman, N., Wong, C., Moser, A., Moser, H. W., Watkins, P., Balle, D., and Gould, S. J . (1995). Mutations in the PTS1 receptor gene, PXR1, define complementation group 2 of the peroxisome biogenesis disorders. Nat. Genet. 9, 115-125.

28. Rapp, S., Soto, U., and J ust, W. W. (1993). Import of firefly luciferase into peroxisomes of permeabilized chinese hamster ovary cells: A model system to study peroxisomal import in vitro. Exp. Cell Res. 205, 59- 65.

29. Subramani, S. (1997). PEX genes on the rise. Nat. Genet. 15, 331-333.

30. Vallee, B. L., and Falchuk, K. H. (1993). The biochemical basis of zinc physiology. Physiol. Rev. 73, 79-117.

31. Suhy, D. A., and O'Halloran, T. V. (1996). Metal-responsive gene regulation and the zinc metalloregulatory model. Metal Ions Biol. Syst. 32, 557-578.

32. Palmiter, R. D., Cole, T. B., and Findley, S. D. (1996). ZnT-2, a mammalian protein that confers resistance to zinc by facilitating vesicular sequestration. EMBO J . 15, 1784-1791.

33. Sirrenberg, C., Endres, M., Folsch, Stuart, R. A., Neupert, W., and Brunner, M. (1998). Carrier protein import into mitochondria mediated by the intermembrane proteins Tim10/Mrs11 and Tim12/Mrs5. Nature 391, 912-915. 